\section{Gold Nanosphere-}

\section{Antibody Conjugates}

for Hyperthermal

\section{Therapeutic}

\section{Applications}

\author{
D Pissuwan ${ }^{1,2}, \mathrm{CH}$ Cortie $^{3}$, SM Valenzuela ${ }^{2}$, \\ MB Cortie ${ }^{1, *}$ \\ ${ }^{1}$ Institute for Nanoscale Technology, University of \\ Technology Sydney, Australia \\ 2 Department of Medical and Molecular Biosciences, \\ University of Technology Sydney, Australia \\ ${ }^{3}$ Visiting Scholar at Institute for Nanoscale Technology \\ * Corresponding author Tel: +61-2-9514-2208 and E- \\ mail:michael.cortie@uts.edu.au
}

\begin{abstract}
Gold nanoparticles can be conjugated with antibodies or other proteins, and the resulting composite particles will selectively attach to various kinds of biological material. Although exploitation of this for staining microscopy specimens is well known, there has recently been interest in attaching gold nanoparticles to live cells for therapeutic reasons. One motivation is that gold nanoparticles display a strong plasmon resonance with light, which can be exploited in principle for an 'in vivo' photothermal therapy. The treatment of cancer by this technique has recently received attention by others, but here we show how gold nanoparticlebased therapies can be developed to target live macrophage cells. We have employed 'active targeting', a scheme in which gold nanoparticles are functionalised with an antibody specific to the target macrophage cell. We describe how to prepare the conjugated particles, demonstrate that they will selectively attach 'in vitro' to their target macrophage cell but not to a non-target cell type and show that their presence renders the target cell susceptible to destruction by a low power laser.
\end{abstract}

Nanoparticles of gold have a growing role in medical biotechnologies [1]. In particular, the pioneering development of immunogold labelling in 1971 [2] has inspired their use in many new diagnostic biological applications [3]. In these technologies the role of the gold is to enhance contrast and resolution in cellular samples examined in an electron microscope. More recently, however, the change in colour that occurs in gold nanoparticle sols on aggregation (or, rarely, de-aggregation [4]) has been used to obtain very sensitive assays for substances such as DNA [5] or, the pregnancy hormone chorionic gonadotrophin [6]. However, in all these instances the techniques are analytical in nature, and obviously applied only to ex situ material. Of course there has also been considerable in vivo use of gold, both colloidal [7] and soluble [8] in Chinese traditional medicine and in quack Western 'medicine' [9, 10]. Furthermore, the revolutionary work of Forestier in the 1930s set the scene for the use of soluble gold organo-metallic compounds for some types of rheumatoid arthritis [10, 11], and similar compounds appear to have some prospects for use in anti-cancer and anti-HIV treatment [10]. Radioactive gold nanoparticles have been used to treat certain cancers since the 1950s [12, 13] while ordinary gold nanoparticles can be used to enhance dosage in radiotherapy [14] and have been intensively investigated as possible drug delivery vectors [1]. It is apparent therefore that the usage of gold in medical applications has a respectable pedigree.

The particular interest in gold nanoparticles is motivated by their unique combination of properties. Three of these are paramount. First, the particles are resistant to oxide formation under ambient conditions, which permits direct engagement of the metallic gold surface with the surrounding environment. This permits the controlled attachment or detachment of organic molecules from the gold surface, as desired, by either exploiting the gold-sulphur bond or electrostatic attraction. Secondly, gold surfaces and gold nanoparticles have unusual optical properties, in particular surface plasmon polaritons and surface plasmon resonances respectively, which are in the visible range of the electromagnetic spectrum. Light absorbed by surface plasmon resonance is converted to heat, which can be exploited to deliver a very localised temperature increase. Finally, gold has a high atomic number, a feature which renders it readily detectable in electron microscopes or by X-rays. The various advantages of gold are neatly brought together in gold-protein conjugate particles, which are formed when gold nanoparticles are encapsulated with a coating of biological material such as a protein or antibody. The biological molecule may be bound to the gold by a covalent bond, or (more commonly) it is attached by electrostatic forces. In either event, gold-protein conjugates are finding broad application in cell biology in general [15], for example as a colorimetric probe for analyzing DNA [5], for protein microarrays [16], detection of GLUT1 in diabetic rats [17], pregnancy testing in humans [6], the detection of 


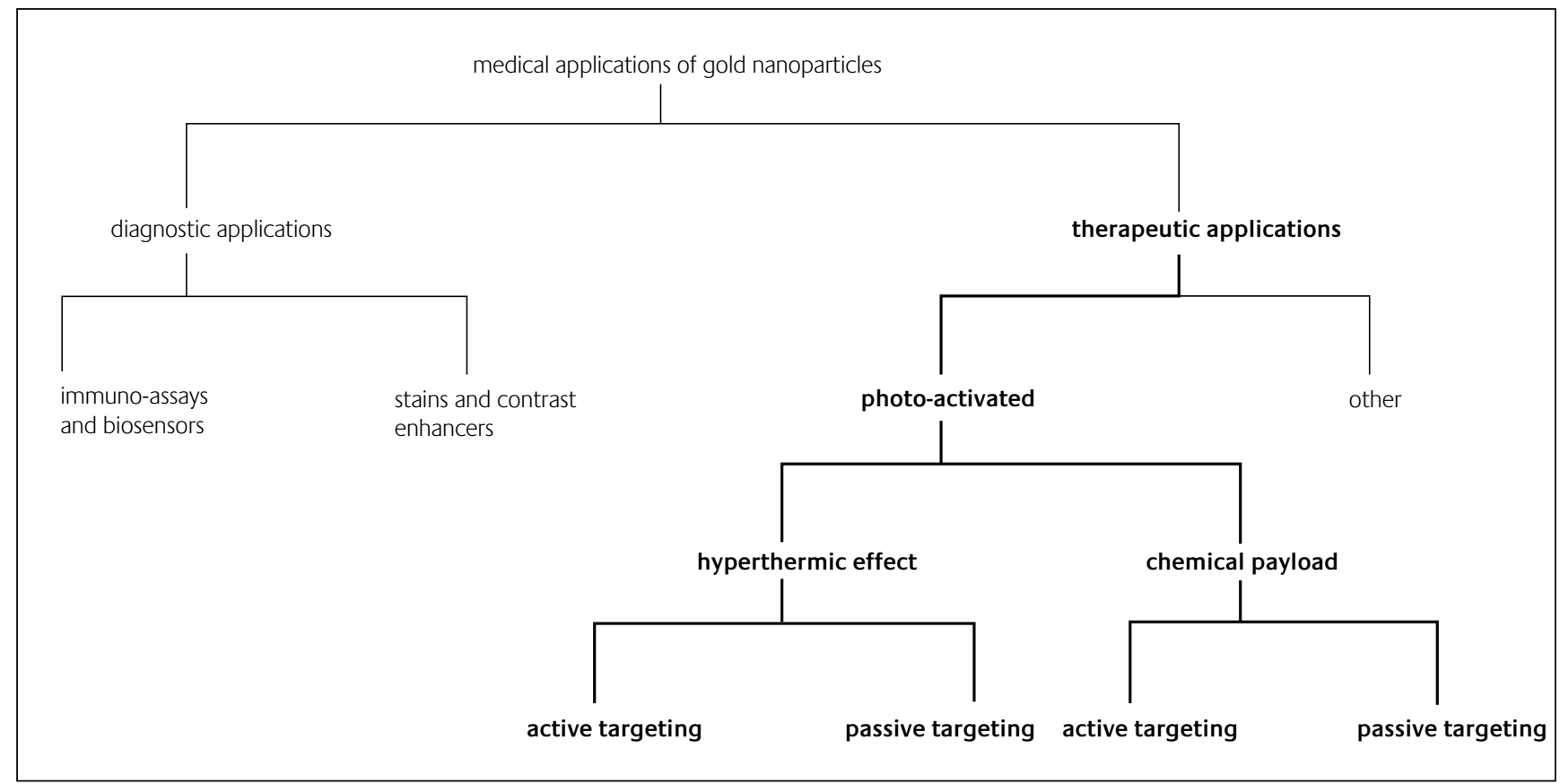

\section{Figure 1}

Classification of the biomedical uses of gold nanoparticles

conformational changes in proteins [18], diverse biosensors [19-22], and to enhance light scattering of targeted cell types in microscopy [23, 24].

However, while the uses of gold nanoparticles in diagnostic applications and of soluble gold compounds in therapeutic applications are now comparatively well known, the rational application of gold nanoparticles in therapeutic situations is a largely undeveloped field. It is this possibility that interests us. In Figure 1, we offer a classification of the existing and potential applications of gold nanoparticles in medical biotechnology, arranged in a taxonomy that is convenient for the present paper. The present article focuses on the branch shown in bold on the diagram, that is, the use of gold nanoparticles for photo-activated therapeutic possibilities. We have recently reviewed progress in this field [25] but since then, there have been several new developments [26-32]). In the present article, however, we focus strictly on gold-protein conjugates developed around spherical gold nanoparticles. There is no space here to comprehensively compare the pros and cons of nanospheres versus nanorods or shells in photothermally activated medical contexts. Suffice it to say that the spheres have a surface plasmon resonance in the mid-visible region of the spectrum (520 to $550 \mathrm{~nm}$, green light) whereas rods and shells can be tuned to absorb at wavelengths from 600 to $1000 \mathrm{~nm}$ (red to near-infrared). However, the response of rods to conjugation with proteins is different to that of spheres. Not only are the former positively charged overall, compared to the negative charge on spheres, but they are usually stabilised with cetyltrimethylammonium bromide (CTAB), a powerful and cytotoxic surfactant, whereas gold nanospheres are usually stabilized with comparatively inert substances such as sodium citrate. Shells, on the other hand, have (so far) not been readily produced in large quantities.
The use of these particles in photothermal medical contexts is predicated upon two overarching principles. First it must be possible to introduce them into the patient in some way that avoids the body's well-honed mechanisms for identifying, neutralizing and removing foreign objects and, secondly, they must become selectively localised in the desired target tissue which must also be within range of a suitable high intensity laser source. The immediate objective of the present research was to investigate the second principle, i.e. the methods by which gold nanospheres can be concentrated in specific live target tissues. Furthermore, while nanoparticles can be concentrated in many tumours by extravasation caused by enhanced permeability of the tumour vessels, or by simple filtration-induced retention (so-called 'passive targeting' [33]), these principles are not of general applicability. Instead we have employed active targeting [33, 34], in which gold nanoparticles are functionalised with an antibody specific to the target cell. The special feature of our work is that we have sought to target macrophage cells rather than cancer cells. Not only are macrophage-based malfunctions key events in auto-immune diseases such as atherosclerosis, diabetes or rheumatoid arthritis, but these cells are also frequently the host for parasitic organisms such as Toxoplasma gondii, Mycobacterium tuberculosis and Listeria monocytogenes [34]. Furthermore, these cells have the natural attribute of attacking and ingesting foreign material in the body anyway, making them an inviting target for nanoparticlebased therapies [34].

\section{Experimental}

The overall experimental methodology is summarised in Figure 2. Spherical gold nanoparticles are conjugated to 


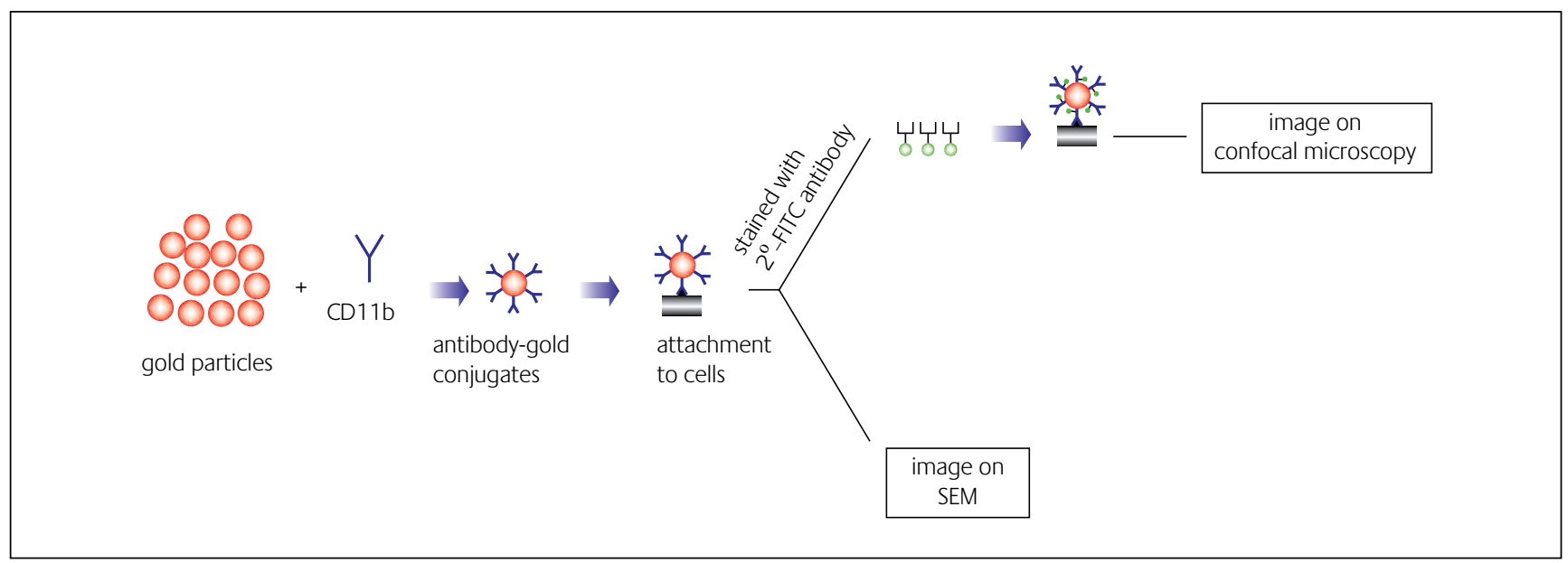

\section{Figure 2}

Schematic illustration of methods by which gold nanoparticles were attached to target cells and characterized

CD11b, an antibody specific to the murine macrophage cells that we have used as our model target. The cell cultures are then exposed to the gold-antibody conjugates, which bind to the outer membranes of the target cells. Following this the nature of this binding is investigated using electron backscatter mode in a scanning electron microscope and, after attaching a fluorescent-tagged secondary antibody to the conjugate, with confocal optical microscopy. Photothermal destruction of the targeted cells is accomplished by irradiating with a laser at a wavelength that induces plasmonic heating in the gold nanoparticles. We investigated the behaviour of 'naked' gold nanoparticles (ie. citrate-stablized particles without attached antibody) and confirmed that they also bound to some extent to live cells, a fact already recorded in the literature $[35,36]$ although they do so to a far lesser degree than if conjugated with a specific antibody [37, 38]. Nevertheless, this rendered the naked gold particles useless as a negative control in the present work. On the other hand, we found that conjugates of gold with bovine serum albumin (BSA) demonstrated greatly reduced levels of non-specific binding to the cells. Therefore gold-BSA conjugates were prepared as one of the controls. In addition, the far lower cost of BSA provided an opportunity to investigate the conjugation process in more detail than was feasible with the CD11b antibody.

The following sub-sections provide detail of the experimental procedures.

\subsection{Preparation of gold spheres}

The preparation of the gold nanospheres followed the standard citrate-reduction route. All glassware used was cleaned in aqua regia ( 3 parts of concentrated $\mathrm{HCl}$ plus to one part of concentrated $\mathrm{HNO}_{3}$ ) before use. $\mathrm{HAuCl}_{4} \cdot 3 \mathrm{H}_{2} \mathrm{O}(1 \mathrm{mM})$ was used as a starting solution. This was transferred to a 250 $\mathrm{ml}$ conical flask for heating and stirred vigorously. When its temperature reached $90^{\circ} \mathrm{C}, 10 \mathrm{ml}$ of $38.8 \mathrm{mM}$ sodium citrate was quickly added. A blue colour immediately developed which changed shortly thereafter to the well-known deep burgundy of gold nanosphere sols. Heating continued for another 15 minutes after which the solution was removed from the heater and stirred for a further 15 minutes. The sol was stored at $4^{\circ} \mathrm{C}$.

\subsection{Conjugation of gold spheres and antibody}

The approach used to conjugate the gold nanoparticles with antibody was based on previously published methods [3, 39]. In brief, the $\mathrm{pH}$ of the gold sol was adjusted to approximately 7.5. Determination of the optimal gold-antibody concentration was achieved using the titration method. In this technique different concentrations of antibody are incubated with the gold nanospheres for 10-15 minutes at room temperature. Following the incubation, the lowest amount of antibody that stabilizes the gold nanoparticles was identified by adding 10\% $\mathrm{NaCl}$. The minimum concentration of antibody that did not exhibit a colour change from burgundy to blue was judged the most suitable amount for conjugation. The principle is that ordinary gold sols are stabilized by electrostatic repulsion between the positively charged nanoparticles. This is screened by the ions in the $10 \% \mathrm{NaCl}$ so the sol aggregates (which makes it turn blue due to particle-to-particle dipole interactions). However, a correctly conjugated nanoparticle is stabilized by steric factors and therefore not sensitive to an increase in the ionic concentration of the solution.

Two kinds of conjugate were prepared, one with bovine serum albumin (BSA) and a second with rat anti-mouse monoclonal antibody (CD11b-Mac1, Chemicon International, California, USA, designated hereafter as 'CD11b'). In both cases the conjugation was carried out after first adjusting the $\mathrm{pH}$ of the sol to 7.5 using small additions of $0.5 \mathrm{M} \mathrm{KOH}$. The proteins were incubated with the sol for 10-15 min, after which unbound antibody or protein in the supernatant was removed by centrifugation at $13000 \mathrm{rpm},+4^{\circ} \mathrm{C}$, for 25 minutes, followed by washing in phosphate saline buffer (PBS; no $\mathrm{Ca}^{2+}$ or $\mathrm{Mg}^{2+}$ ). The antibody- or BSA-conjugated gold pellet was then re-suspended in PBS plus 1\% bovine serum albumin (BSA). The absorbance of the working solution was adjusted to 0.6 at $530 \mathrm{~nm}$ by dilution.

Protein analyses were done by the bicinchoninic acid method (BCA protein assay). Briefly, $10 \mu$ of supernatant was 

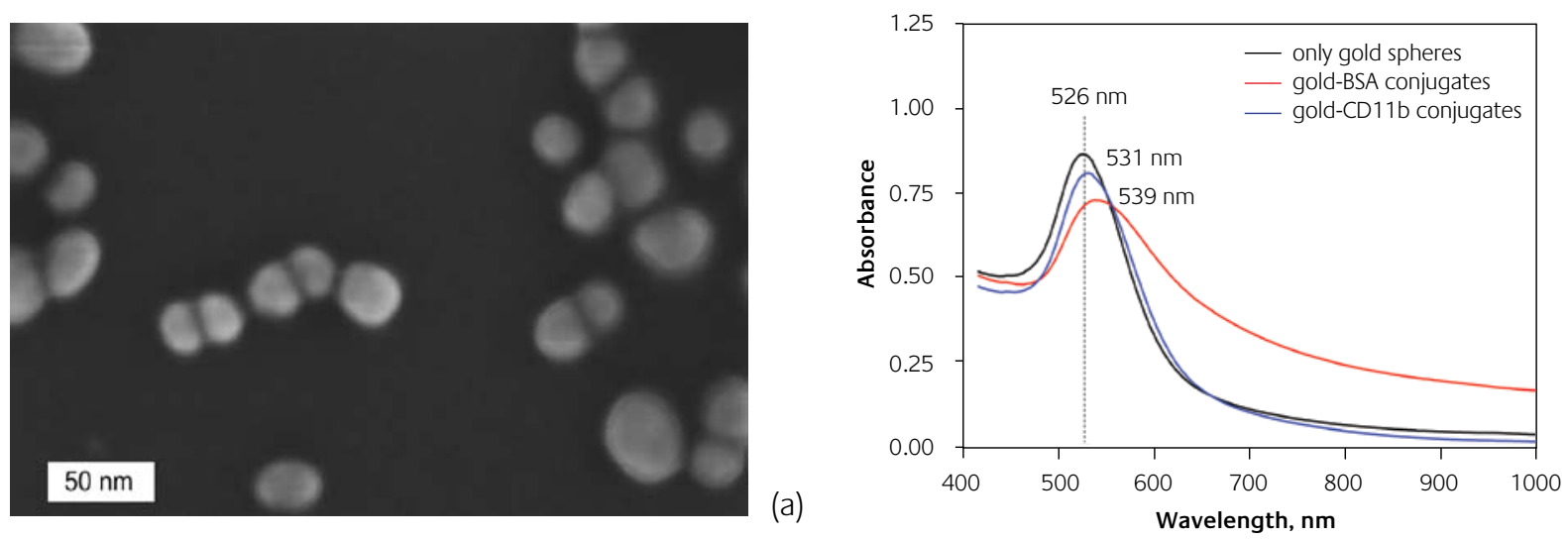

(b)

\section{Figure 3}

Basic citrate-stabilized gold nanospheres on which the conjugation were based. (a) Image of unconjugated gold nanospheres taken using an electron microscope, (b) Optical extinction of colloidal suspensions showing plasmon peak at 526 nm and the red-shifting effect of conjugation with proteins $B S A$ and $C D 11 b$

mixed with $200 \mu \mathrm{l}$ working reagent ( BCA Reagent A and B, Pierce, USA) by shaking for 30 seconds. The mixed solution was then incubated at $37^{\circ} \mathrm{C}$ for 30 minutes after which the absorbance at $560 \mathrm{~nm}$ was measured on a microplate reader. A standard solution of $1 \mathrm{mg} / \mathrm{ml}$ BSA was used for calibration. Unfortunately, protein analysis of the gold pellet could not be reliably undertaken due to interference from the colour of the colloid itself.

\subsection{Cell preparation and labelling}

Murine macrophage cells (Raw 264.7) and Chinese hamster ovary cells (CHO-K1) were cultured on glass cover slips in Dulbecco's modified Eagle's medium/Ham's nutrient mixture F-12(DMEM-F12, JRH Biosciences) including $2 \mathrm{mM}$ glutamine supplemented with $10 \%$ fetal bovine serum (FBS, JRH Bioscience). Cells were seeded onto glass coverslips at $1 \times 10^{5}$ cells $/ \mathrm{ml}$ and maintained in a humidified incubator at $37^{\circ} \mathrm{C}$ and $5 \% \mathrm{CO}_{2}$ for 48 hours. Labelling of the cells was accomplished

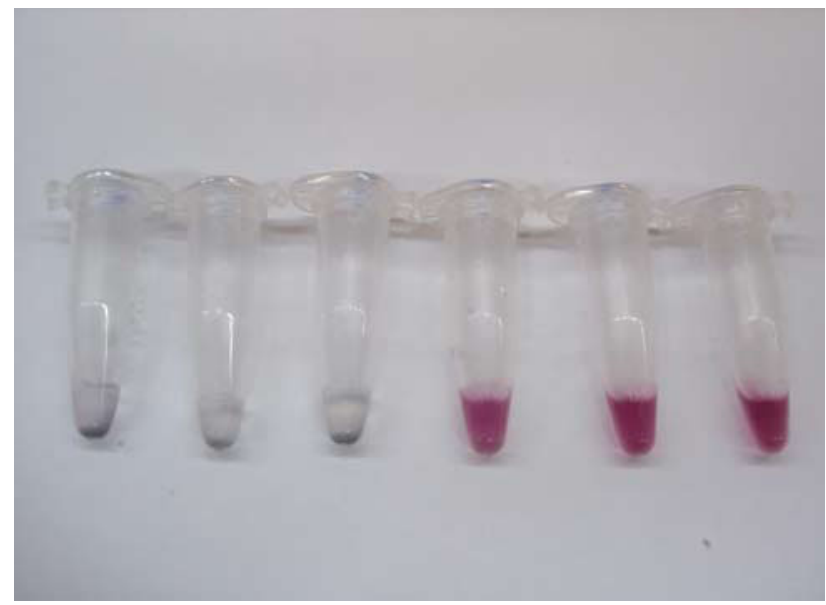

\section{Figure 4}

Concentration gradient of BSA/gold nanoparticle mixtures. The three tubes on the left contain insufficient BSA to stabilize the colloid when concentrated $\mathrm{NaCl}$ solution is added. The optimum concentration of $B S A$ is that of the fourth tube. The fifth and sixth tubes contain excess BSA that must be removed by centrifugation and washing by incubating them with gold-antibody conjugates in PBS plus $1 \% \mathrm{BSA}$ for 1 hour at $37^{\circ} \mathrm{C}$ and under $5 \% \mathrm{CO}_{2}$, and washed four times with PBS plus 1\% BSA to remove unbound gold-antibody conjugates. Negative controls included the incubation of gold-BSA conjugates with the macrophage cells, and the incubation of gold-CD11b conjugates with the CHO-K1 cells.

\subsection{Microscopy}

Cells labelled with gold spheres (as outlined above) were fixed with $4 \%$ paraformaldehyde in PBS for 25 minutes at room temperature. For optical microscopy the cells were then incubated with a secondary FITC (fluorescein isothiocyanate) antibody (goat anti-rat IgG-FITC; Sigma-Aldrich, MO, USA, designated hereafter as ' $2^{\circ} \mathrm{abFITC')} \mathrm{at} \mathrm{a} \mathrm{dilution} \mathrm{of} \mathrm{1:30}$ for 1 hour at $37^{\circ} \mathrm{C}$. Cells were washed four times with PBS to remove unbound secondary FITC and viewed under a confocal microscope (FV300, Olympus). The purpose of the secondary antibody, which is fluorescent, was to provide a clear visualization of the location of all active CD11b antibodies. To observe endocytosis of gold nanoparticles by the macrophage cells, an experiment was done as above but without fixation.

For scanning electron microscopy the cells were fixed as described before, then washed four times with PBS and six times with Milli-Q water. The cover slips were then dried and stored in a desiccator until imaged.

\subsection{Irradiation by laser}

The mature murine macrophage cells were incubated with conjugated and unconjugated gold nanoparticles. Following this the cells were irradiated for 10 minutes by a $543.5 \mathrm{~nm}$ green HeNe laser with a core size (determined using laser burn paper) of $0.1 \mathrm{~mm}$ (although to the eye the spot size appeared closer to $2 \mathrm{~mm}$ ). The power of the laser was measured to be $\sim 2.5 \mathrm{~mW}$ using a power meter. Thereafter, the cells were incubated for an hour at $37^{\circ} \mathrm{C}$ and their viability checked by using SYTOX green nucleic 


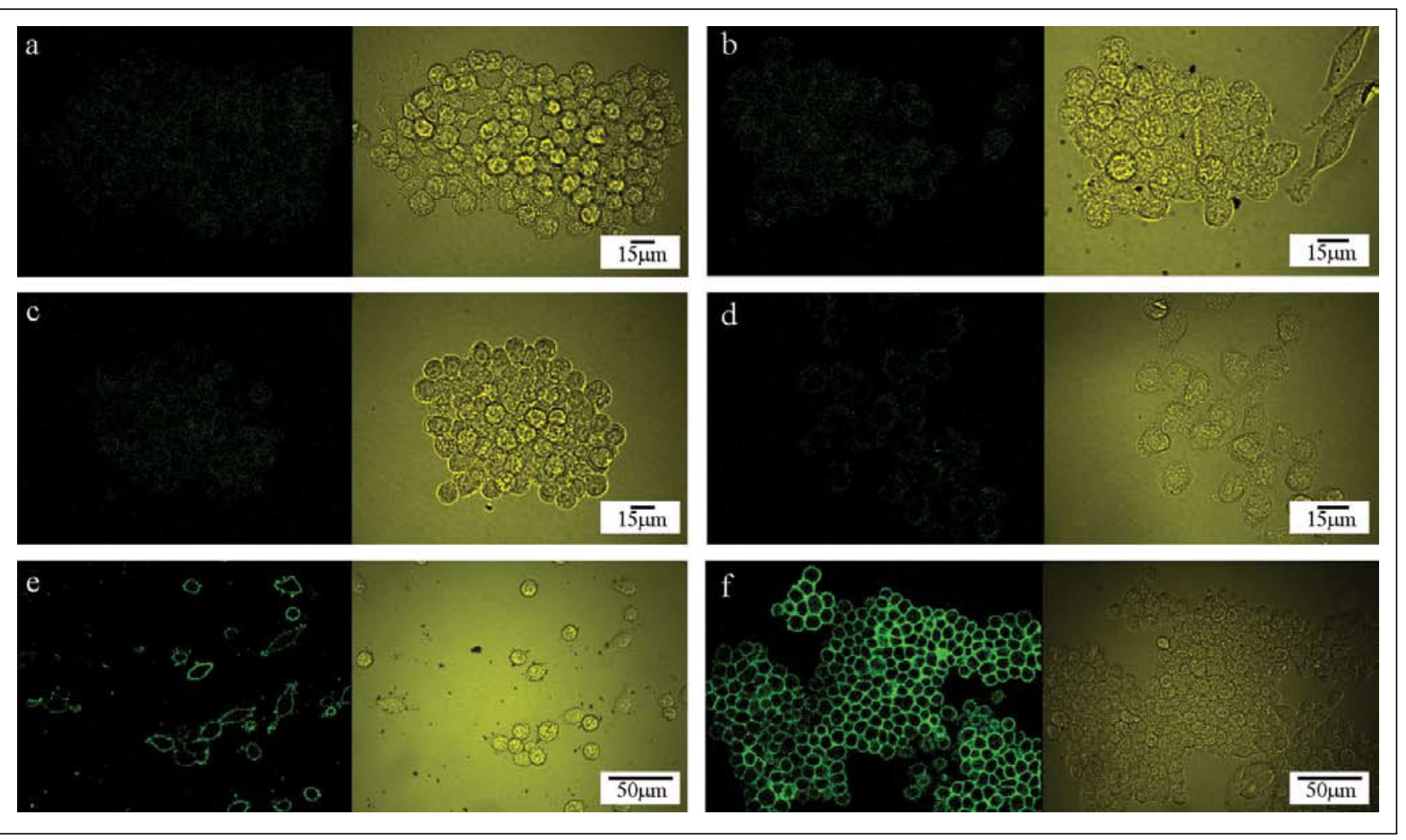

\section{Figure 5}

Fluorescent (left) and transmitted light (right) images of various samples of live cells. (a) macrophage (Raw 264.7) cells incubated with gold and CD11b, (b) macrophage cells incubated only with gold/BSA conjugates followed by exposure to $2^{\circ}$ abFITC, (c) macrophage cells incubated with $2^{\circ}$ abFITC only, (d) CHO-K1 cells incubated with gold/CD11b conjugates, followed exposure to $2^{\circ}$ abFITC (e) macrophage cells plus Au/CD11b conjugates followed by exposure to $2^{\circ}$ abFITC, (f) macrophage cells incubated with CD $11 \mathrm{~b}$ followed by exposure to $2^{\circ}$ abFITC

acid stain (Invitrogen, California, USA). Macrophages were also incubated with gold-BSA conjugates as the negative control.

\section{$3 \quad$ Results}

\subsection{Gold-protein conjugates}

The citrate-stabilised gold nanoparticles and their optical extinction spectrum are illustrated in Figure 3. The particles have a nominal diameter of $\sim 20 \mathrm{~nm}$ (Figure 3a) and are well dispersed while in colloidal suspension (as attested to by their optical spectra which showed an absorption peak at 526 $\mathrm{nm}$, Figure 3b). Conjugation of the particles with the BSA was straightforward, and a clear-cut transition from stable to unstable conditions achieved at a BSA/Au mass ratio of close to 1 (Figure 4). However, protein analyses of the supernatant fluid showed that, even under these supposedly optimum conditions, approximately $90 \%$ of the added BSA was actually present in the supernatant, with only 10\% actually bound to gold nanoparticles. This excess protein was removed by the centrifugation and wash cycle, after which the pellet was resuspended.

The surface loading of BSA onto citrate-stabilised gold nanoparticles has been measured by Brewer et al. [40] and by De Roe et al. [41] who established that complete coverage is associated with between $3.7 \times 10^{12}$ and $6.2 \times 10^{12}$ molecules per $\mathrm{cm}^{2}$. The molecular weight of BSA is of the order of
$66 \times 10^{3}$ daltons, so such a complete monolayer coverage on a monodispersed population of $20 \mathrm{~nm}$ diameter gold nanospheres would give a BSA:Au mass ratio of between 0.06 and 0.10. As mentioned, our measurement was in the vicinity of 0.10 . This corresponds to about 74 BSA molecules associated with each nanoparticle (since an individual BSA molecule has a mass of about $1.096 \times 10^{-16} \mathrm{mg}$ and an individual gold nanosphere of $20 \mathrm{~nm}$ diameter a mass of $8.08 \times 10^{-14} \mathrm{mg}$ ). The size of a BSA molecule is variously given as $5 \times 5 \times 5 \mathrm{~nm}$ [42] or $5.5 \times 5.5 \times 9 \mathrm{~nm}$ [40] from which it can be estimated that around 40 to 50 BSA molecules would be required to form a monolayer on the gold nanoparticle. Either way, the figures are in reasonable agreement with our experimental results, given that some free BSA is still likely to be present in the pellet, that the protein analyses had limited accuracy, and, finally, that the gold particles were not actually monodisperse.

A less clear-cut transition was obtained when conjugating with the CD11b antibody compared with gold-BSA conjugates. In this case, the molecular weight of CD11b antibody (about $170 \mathrm{KDa}$ ) is larger than BSA (66KDa) resulting in far fewer of the more bulky CD11b molecules being attached to each gold nanoparticle. The optimum concentration of CD11b was in the vicinity of $0.3 \mathrm{mg} / \mathrm{ml}$. Calculations indicated that, on average, of the order of four or five CD11b molecules were attached to each gold nanoparticle. The plasmon resonance of the particles was slightly red-shifted after conjugation with either BSA or CD11b (see Figure 3b). 


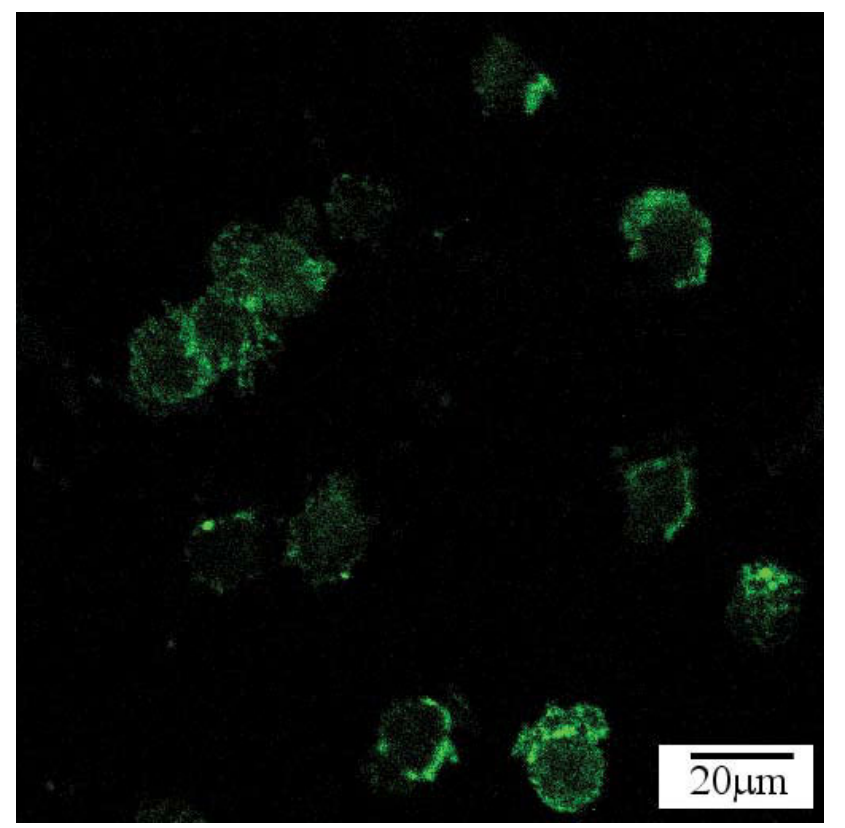

Figure 6

Macrophage cells that have been incubated with gold -CD11b and $2^{\circ}$ abFITC particles for one hour. The gold particles appear to have been taken up into the cells by endocytosis, and a proportion of them are visible as granular green concentrations within the cell. These concentrations presumably correspond to the lysosomes that are encapsulating the particles which are still fluorescent (eg. Shukla et al.[36])

\subsection{Selective attachment to live cells}

As hoped, the gold-CD11b conjugates bound to the macrophage cells but not to the CHO-K1 cells. The distribution of gold nanoparticles on the surface of cells was seen as bright spots by using scanning electron microscopy in backscatter mode. In contrast, there were no or few bright spots on macrophage cells not incubated with gold-antibody conjugates, or on the $\mathrm{CHO}$ cells.

More detail was obtained when the cells were examined in a confocal optical microscope. In order to visualise the goldCD11b stained cells, a secondary anti-mouse FITC conjugate was used. In this case fluorescent staining was observed around the periphery of macrophage cells (Figure 5e) that had been incubated with the gold-CD11b antibody conjugates. As expected, no fluorescence staining was noted in the samples lacking secondary FITC antibody (Figure 5a). Similarly, CHO-K1 cells stained with the gold-CD11b followed by the secondary FITC conjugate showed no fluorescent staining (Figure 5d), indicating that the gold-CD11b conjugate had no affinity for these cells. Similarly incubating the RAW cells with the secondary FITC antibody alone also did not cause any fluorescent staining (Figure $5 c$ ). To confirm the normal staining pattern of CD11b, macrophage cells were stained with this antibody followed by exposure to the secondary antibody. These cells demonstrated the same strong staining of the cell periphery (Figure 5f) as was seen for the goldCD11b conjugates (Figure 5e). Finally, macrophage cells were exposed to gold-BSA conjugates and then incubated with the secondary antibody. No staining took place in this case (Figure 5b).

In another experiment the RAW cells were incubated with CD11b / FITC conjugated gold nanoparticles for a period of one hour. This time is sufficient to allow the process of endocytosis (the process by which many cells engulf and ingest external macromolecules or particles) to occur. The
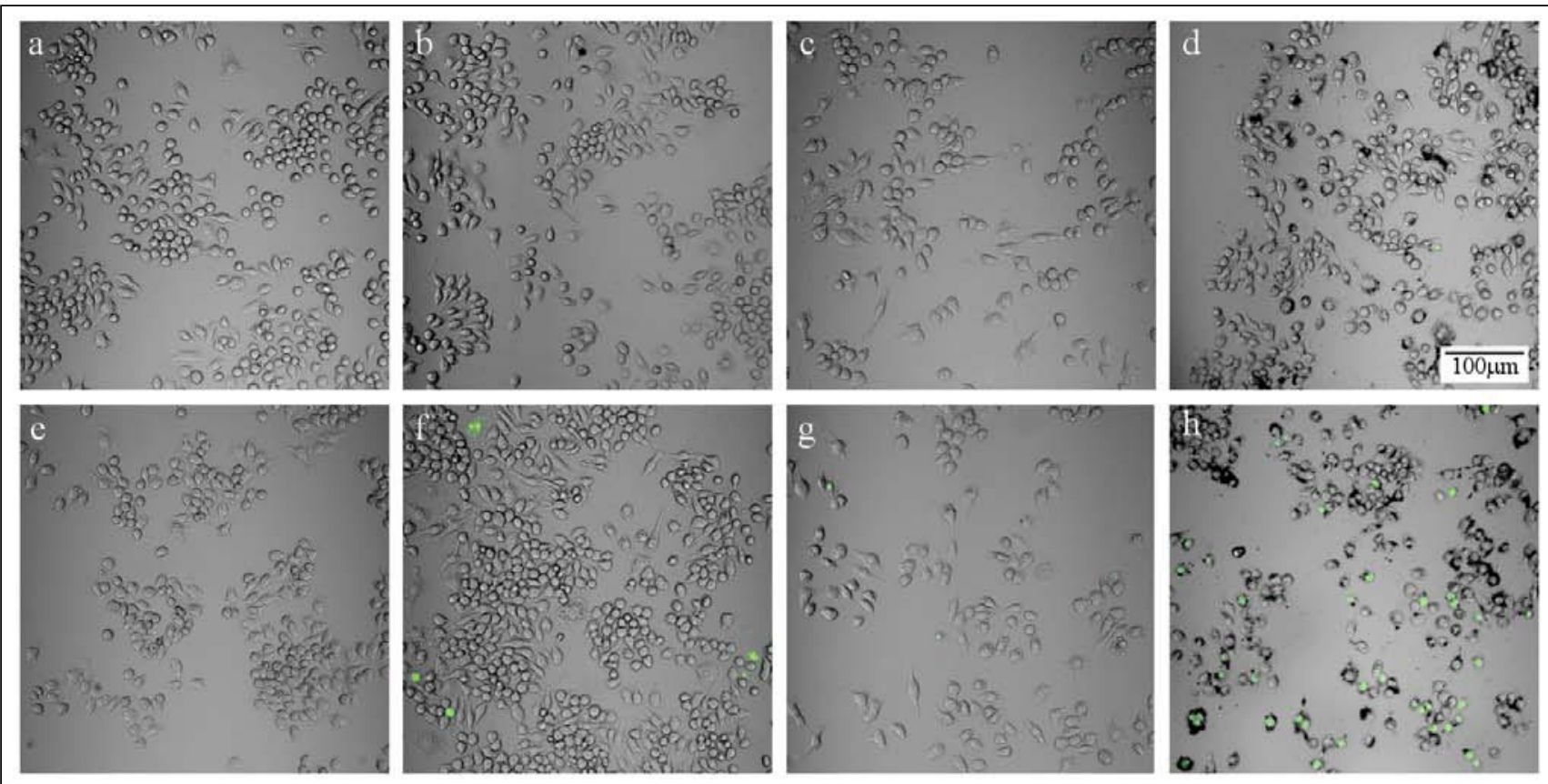

\section{Figure 7}

Effect of laser irradiation on cells treated with various types of gold nanoparticles. The dead cells glow green under the fluorescent mode of the confocal microscope. Top row, no irradiation, bottom row, after irradiation with a HeNe green laser at a wavelength $543.5 \mathrm{~nm}$ for 10 minutes. (a \& e) Cells only, no gold, (b \& f) cells incubated with naked gold nanoparticles, (c \& g) cells incubated with gold-BSA conjugates, (d \& h) cells incubated with gold-CD11b antibody conjugates 
Table 1

Cell death rates with and without gold-protein conjugate particles and laser irradiation

\begin{tabular}{|c|c|c|c|c|c|c|c|c|}
\hline Treatment & C & $\mathrm{CL}$ & CG & CGL & CGBSA & CGBSAL & CGAb & CGAbL \\
\hline Percentage of dead cells & 0.46 & 0.11 & 0.76 & 1.35 & 0.23 & 0.61 & 0.80 & 25.42 \\
\hline Standard deviation (\%) & \pm 0.46 & \pm 0.61 & \pm 0.82 & \pm 0.95 & \pm 0.33 & \pm 0.58 & \pm 0.54 & \pm 6.26 \\
\hline $\begin{array}{l}\text { Total number of } \\
\text { counted cells ( } n \text { ) }\end{array}$ & 6544 & 5406 & 6198 & 4669 & 3047 & 980 & 3506 & 2030 \\
\hline
\end{tabular}

Key

$\mathrm{C}=\quad$ Only macrophages

$\mathrm{CL}=\quad$ Macrophages exposed with a laser

$\mathrm{CG}=\quad$ Macrophages attached with naked gold nanoparticles

$\mathrm{CGL}=\quad$ Macrophages attached with naked gold nanoparticles and exposed with a laser

CGBSA = Macrophages attached with gold-BSA conjugates

CCBSAL = Macrophages attached with gold-BSA conjugates and exposed with a laser

$C G A b=$ Macrophages attached with gold-CD11b antibody conjugates

$\mathrm{CCAbL}=$ Macrophages attached with gold-CD11b antibody conjugates and exposed with a laser

result is shown in Figure 6. Close examination of that figure indicates that the FITC dye (and hence presumably the gold nanoparticles to which it was bound) is present on the surface of the cells, and also in patchy regions within them. The usual process with macrophage cells is that they take up foreign material by endocytosis, in the process of which the material is encapsulated in a lysosome within the cytoplasm. The patchy appearance of dye within the cells is compatible with this possibility, which has also been suggested by others [36].

These results demonstrate that the CD11b antibody conjugated to gold nanospheres bound selectively to its target macrophage cells and was internalized by them. This event did not take place to any significant extent in the $\mathrm{CHO}$ K1 cells. Similarly, the control gold-BSA / FITC conjugates did not demonstrate significant binding or internalization to the macrophage or $\mathrm{CHO}-\mathrm{K} 1$ cells.

\subsection{Laser irradiation of cells}

The effect of irradiating the macrophage cells with and without the various kinds of gold nanoparticles is shown in Table 1 and Figure 7. After staining with SYTOX green dye, negligible cell death was observed in the samples not exposed to laser irradiation. Negligible cell death was also demonstrated in samples that had not been pre-treated with gold nanoparticles conjugated with antibody but that were then exposed to laser irradiation at the same laser fluencies and the same exposure time. In contrast, the death rate for cells that had been pre-incubated with gold-antibody conjugate followed by laser irradiation was found to increase to at least $25 \%$. It is evident from this result that photothermal heating of the gold nanoparticles strongly affects cell viability of target cells. In fact the percentage of dead cells is likely to have been higher than what is reported here, given that the laser has a Gaussian distribution of intensity and the area counted under the microscope ( $2 \mathrm{~mm}$ diameter) exceeded the zone of maximum laser intensity ( $0.1 \mathrm{~mm}$ diameter).
Macrophage cells pre-incubated with naked gold showed very low levels of cell death $(\sim 1 \%)$, indicating that there was negligible non-specific binding of the gold particles to the cells. A similar result was achieved in cells pre-incubated with gold-BSA conjugates, showing an even lower death rate of $0.61 \%$ following laser exposure. These results further confirm that cells exposed to laser irradiation with no bound gold were not susceptible to the energy of the laser. These results are statistically significant and demonstrate the principle of specific cell targeting and targeted cell death.

\section{Discussion}

This paper has focused on the preparation and characterization of a gold-antibody conjugate that selectively binds to a live macrophage cell line, which then allows for the selective photothermal destruction of the target cell. It is however well worth discussing the therapeutic directions that this capability might head towards, of which there are two significant possibilities:

In the first scenario the gold-antibody conjugates are bound to, or taken up by, the target cell, and then laser illumination at a suitable wavelength is applied to the relevant region of the patient. The particles will then absorb the radiation and heat up. The gold-antibody conjugates themselves would have to be introduced intravenously into the patient, and there are some practical difficulties that might be expected. However, there has already been considerable progress made in respect to passively targeting cancer cells by such means e.g. [14, 43, 44], with some encouraging reports involving active targeting of cancer cells e.g. $[23,31,45]$ and, rather more rarely, reports of other target organisms such as bacteria, rather than eukaryotic cells [37]. If pulsed laser radiation is applied, then comparatively high laser intensities are required to produce a lethal temperature change of, for example, $15^{\circ} \mathrm{C}$, in the vicinity of the gold particles. However, 
in this paper, we have used a continuous wave radiation from a green laser at wavelength $543.5 \mathrm{~nm}$, applied for a few minutes. A similar effect was also produced using far lower intensities of radiation with a laser power value of 2.5 $\mathrm{mW}$, but applied for longer times. The gold nanoparticles strongly absorbed light from the laser due to the overlapping of surface plasmon absorption band between the laser (543.5 nm) and gold nanoparticles (526 nm). This light absorption by the gold nanoparticles is then converted into heat by electron-phonon and phonon-phonon processes [46] resulting in the destruction of targeted cells The important criterion, it seems, is that a fluence of at least $1 \mathrm{~J} / \mathrm{cm}^{2}$ be delivered [47]. In either case the desired outcome is death of the target cell by hyperthermia. Of course, the survivability of individual cells when challenged by a rise in temperature will exhibit some statistical variation, and similarly there is a source of variation due to the fact that individual cells might have different numbers of gold particles attached. However, in contrast, control macrophage cells that did not have attached gold nanoparticles demonstrated no hyperthermal mortality when irradiated by laser, probably because of the near-transparency of the natural endogenous cytochromes at the wavelength used [37].

It will obviously be important to further characterise the energy threshold required to kill a cell. This depends on the power density arising from the laser light, on the number of gold particles on the surface of the cell, and the individual properties of the specific cell type. In the current experiments a relatively low power density laser was used, resulting in about $25 \%$ cell death. Use of a higher power density would result in an increased number of dead cells in a given time [48], or a similar death rate can be obtained but with a smaller number of gold particles attached to each cell or the same density of gold nanoparticles but a shorter exposure time. The use of gold nanoparticles provides new flexibility which might overcome the side effects of conventional photodynamic therapy based on the light activation of dyes [49].

The second scenario in which the phenomena described could be exploited is more subtle. In this instance the desired effect is that the gold-organic conjugate enters the target cell, either through a temporarily permeablized cell membrane, or by the naturally occurring process of endocytosis. The payload in this case is not necessarily hyperthermia, but could also be the organic component conjugated to the gold nanoparticle, for example tumour necrosis factor (TNF) [13] or even genetic material [1]. Either way, a gold nanoparticle conjugate provides a convenient vehicle for delivery, and low power plasmonic heating of the gold nanoparticle might additionally provide the means either to permeabilize the cell membrane and/or to liberate a molecular payload [13, $26,28,44,45,50]$. Macrophage cells can act as host cells for some pathogenic microorganisms [34] and temporary permeabilization of their membranes to permit the ingress of some large drug molecules could be useful. Alternatively, the scheme could be developed to deliver gene transfection or gene therapy.
Finally, it may be worth commenting on an apparent anomaly, also noted by others in the literature [40]. The isoelectric point of BSA is 4.6, so it would be negatively charged at a pH of greater magnitude. Secondly, it is wellestablished that proteins prefer to bind to a surface of opposite charge. [42]. Unfortunately, citrate-stabilized Au nanoparticles are also negatively charged (-40 to $-50 \mathrm{mV}$ depending on $\mathrm{pH}[13,40])$. So how is it possible that the protein is bound to the gold at neutral values of $\mathrm{pH}$ ? Brewer et al. [40] postulate that it was actually surface lysine groups in the BSA that bound to the Au, overcoming the overall unfavourable charge distribution on the protein. This point has a direct bearing on the conjugation process and probably deserves more attention in future.

\section{Conclusions}

Gold nanoparticles have been functionalised with an antibody against a particular macrophage cell, and the resultant conjugated particles show selective binding to their live target. Selective destruction of the target cell line is then possible by applying laser irradiation with a laser tuned to the plasmon resonant frequency of the gold nanoparticles. Availability of these particles and wider knowledge of their properties should facilitate the development of activelytargeted photothermal therapeutic treatments.

\section{About the authors}

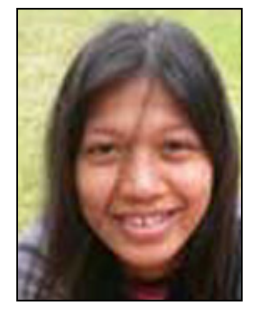

Ms Dakrong Pissuwan holds degrees from Srinakharinwirote University and King Mongkut's University of Technology Thonburi, both in Thailand. She is currently a PhD student at the University of Technology Sydney, Australia. Her research is directed towards developing antibody-targeting of gold nanoparticles for possible therapeutic applications.

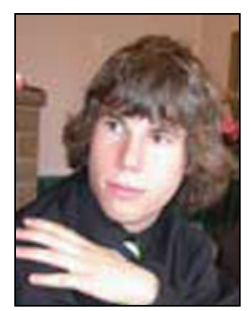

Mr Colin Cortie is a biological sciences student in the Faculty of Science at the University of Wollongong, Australia. His contribution to the current work arose in the course of a vacation work project on gold nanoparticle-antibody conjugation conducted at the University of Technology, Sydney.

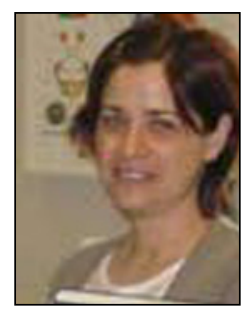

Dr Stella M. Valenzuela is a Lecturer in the Department of Medical and Molecular Biosciences at the University of Technology Sydney, Australia. She is a graduate of the Universities of New South Wales and Sydney, Australia. Her research interest is the structure and function of membrane proteins, with a particular focus on CLIC ion channel proteins. 


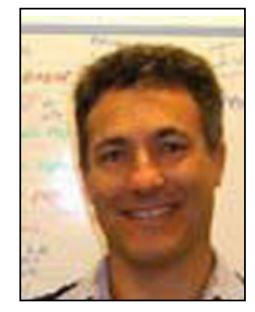

Prof. Michael Cortie is the Director of the Institute for Nanoscale Technology at the University of Technology Sydney. The Institute specialises in the optical properties of materials at the nanoscale, and in precious metals nanotechnology. Michael is a graduate of the Universities of Witwatersrand and Pretoria, in South Africa but now resides in Australia.

\section{References}

1 W. R. Glomm, J. of Dispersion Sci. and Technol., 2005, 26, 389

2 W. P. Faulk \& G. Taylor, Immunochem., 1971, 8, 1081

3 M. A. Hayat. Colloidal Gold: Principles, Methods, and Applications (Academic Press, San Diego, CA, 1989)

4 S. - Y. Lin, S.-H. Wu \& C.-H. Chen, Angew. Chem. Int. Ed., 2006, 45, 4948

5 R. Elghanian, J. J. Storhoff, R. C. Mucic, R. L. Letsinger \& C. A. Mirkin, Sci., 1997, 277, 1078

6 C. R. Martin \& D. T. Mitchell, Anal. Chem. News \& Features, 1998, 1st May, 322A

7 D. G. Richards, D. L. McMillin, E. A. Mein \& C. D. Nelson, Intern. J. Neuroscience, 2002, 112, 31

8 Z. Huaizhi \& N. Yuantao, Gold Bull., 2001, 34, 24

9 M. - C. Daniel \& D. Astruc, Chem. Rev. , 2004, 104, 293

10 C. F. Shaw, Chem Rev., 1999, 99, 2589

11 R. Eisler, Inflammation Research, 2003, 52, 487

12 H. E. Harding, J. Clin. Path., 1953, 6, 149

13 G. F. Paciotti et al., Drug Delivery, 2004, 11, 169

14 J. F. Hainfeld, D. N. Slatkin \& H. M. Smilowitz, Phys. Med. Biol., 2004, 49, N309-N315

15 J. F. Hainfeld \& R. D. Powell, J. Histo. Cyto., 2000, 48, 471

16 R. - Q. Liang et al., Nucl. Acids Res., 2005, 33, e17

17 R. Fernandes, K. Suzuki \& A. K. Kumagai, IOVS, 2003, 44, 3150

18 S. Chah, M. R. Hammond \& R. N. Zare, Chem. \& Biol., 2005, 12, 323

19 D. J. Maxwell, J. R. Taylor \& S. Nie, J. Am. Chem.Soc., 2002, 124, 9606

20 C. - X. Lei, F.-C. Gong, G.-L. Shen \& R.-Q. Yu, Sens. Act. B, 2003, 96, $582-588$

21 A. T. A. Jenkins, R. French-constant, A. Buckling, D. J. Clarke \& K. Jarvis,
Biotechnol. Prog., 2004, 20, 1233

22 H. Wang et al., Biosens. Bioelec., 2004, 19, 701

23 C. Loo et al., Technol. in Cancer Res. \& Treatment, 2004, 3, 33

24 B. Wiley et al., MRS Bulletin, 2005, 30, 356

25 D. Pissuwan, S. Valenzuela \& M. B. Cortie, Trends Biotechnol., 2006, 24,62

26 C. - C. Chen et al., J. Am. Chem. Soc., 2006, 128, 3709

27 H. Takahashi, T. Niidome, A. Nariai, Y. Niidome \& S. Yamada, Chem. Lett., $2006,35,500$

28 H. Takahashi, Y. Niidome \& S. Yamada, Chem. Commun., 2005, 2247

29 I. H. El-Sayed, X. Huang \& M. A. El-Sayed, Cancer Lett., 2006, 239, 129

30 I. H. El-Sayed, X. Huang \& M. A. El-Sayed, Nano Lett., 2005, 5, 829

31 X. Huang, I. H. El-Sayed, W. Qian \& M. A. El-Sayed, J. Am. Chem. Soc., 2006, 128, 2115

32 Z. Krpetic, F. Porta \& G. Scarì, Gold Bull., 2006, 39, 66

33 S. E. McNeil, J. Leukoc. Biol. , 2005, 78, 585-594

34 S. M. Moghimi, A. C. Hunter \& J. C. Murray, FASEB J., 2005, 19, 311

35 B. D. Chithrani, A. A. Chazani \& W. C. W. Chan, Nano Lett., 2006, 6,662

36 R. Shukla et al., Langmuir, 2005, 21, 10644

37 V. P. Zharov, K. E. Mercer, E. N. Galitovskaya \& M. S. Smeltzer, Biophys. J., 2006, 90, 619

38 D. Lapotko et al., Proceedings of SPIE, 2005, 5697, 82

39 J. W. Slot \& H. J. Geuze, Eur. J. Cell Biol., 1985, 38, 87

40 S. H. Brewer, W. R. Glomm, M. C. Johnson, M. K. Knag \& S. Franzen, Langmuir, 2005, 21, 9303

41 C. De Roe, P. J. Courtoy \& P. Baudhuin, J. Histochem. Cytochem., 1987, 35, 1191

42 K. Rezwan, L. P. Meier \& L. J. Gauckler, Biomaterials, 2005, 26, 4351

43 D. P. O’Neal, L. R. Hirsch, N. J. Halas, J. D. Payne \& J. L. West, Cancer Lett., 2004, 209, 171

44 L. R. Hirsch, J. B. Jackson, A. Lee, N. J. Halas \& J. L. West, Anal. Chem., 2003, 75, 2377

45 C. M. Pitsillides, E. K. Joe, X. Wei, R. R. Anderson \& C. P. Lin, Biophys. J., $2003,84,4023$

46 S. Link \& M. A. El-Sayed, Inter. Rev. Phys. Chem., 2000, 19, 409

47 D. O. Lapotko \& V. P. Zharov, Lasers Surg. Med., 2005, 36, 22

48 X. Huang, P. K. Jain, I. H. El-Sayed \& M. A. El-Sayed, Photochem. Photobiol., 2006, 82, 412

49 O. Salata, J. Nanobiotechnology, 2004, 2, 3 doi:10.1186/1477

50 C. Yao et al., J. Biomed. Optics, 2005, 10, 064012 